\title{
Simulation on the Time Progress of the Non-Point Source Pollution Load in Initial Stage Runoff for Small Watershed
}

\author{
Mingyuan Sun ${ }^{1,2}$, Tiantian Liu'2, Bo Chen², Yi Zhang2, Longxi Han1,2 \\ ${ }^{1}$ Key Laboratory of Integrated Regulation and Resource Development on Shallow Lake of Ministry of Education, College of \\ Environment, Hohai University, Nanjing, China \\ ${ }^{2}$ College of Environment, Hohai University, Nanjing, China \\ Email: 15705186993@163.com
}

How to cite this paper: Sun, M.Y., Liu, T.T., Chen, B., Zhang, Y. and Han, L.X. (2017) Simulation on the Time Progress of the Non-Point Source Pollution Load in Initial Stage Runoff for Small Watershed. World Journal of Engineering and Technology, 5, 62-70.

https://doi.org/10.4236/wjet.2017.53B008

Received: June 16, 2017

Accepted: August 8, 2017

Published: August 11, 2017

\begin{abstract}
Taking a reservoir in South China as an example, we use rainfall-runoff unit hydrograph method to analyze the time changing process of surface runoff inflow, which generated by typical design rainfall. On the basis of time series data of flow and water quality in control section of the main rivers in Xili Reservoir, we establish mathematical response relation between non-point source pollutants flux, such as flux of COD, flux of NH3-H, in catchment area of control section and runoff. Then we simulate the time dynamic change progress of non-point source pollution load which generate with the initial stage runoff that generated by design rainfall and flow into reservoir. It can provide technical parameters for the design of non-point source which generate from early runoff treatment project.
\end{abstract}

\section{Keywords}

Small Watershed, Initial Runoff, Non-Point Source Pollution Load, Time Change Process

\section{Introduction}

With the further development of point source pollution control, point source pollution has been initially controlled. However, the proportion of non-point source pollution is increasing in China [1] [2]. It has been the main object of comprehensive treatment of water pollution. Non-point source pollution accumulates on the surface of the earth and pollutes water bodies by the rainfall erosion and surface transportation. Due to the complexity and variety of pollutants 
and it is affected by many complex factors, non-point source pollutions have the characteristics of randomness, long-term, hysteresis, uncertainty and so on [3].

The research on non-point source pollution has been carried out as early as 1970s. Foreign scholars often use ARM, SWMM, STORM and other non-point source pollution calculation model for non-point source pollution load [4] [5]. Due to the late start of the study of non-point source pollution in China, scholars in China generally revise the existing models. At present, the main methods of non-point source pollution load estimation are mechanistic model and empirical model [6], for example, based on the method of non-point source pollution load output coefficient, Long, et al. [7] introduce the pollution load coefficient and establish a mathematical model for nitrogen and phosphorus load in non-point sources. Then he forecast the total annual load of non-point source nitrogen and phosphorus in the Three Gorges Reservoir Area in 2020 by combining with distributed SLUP hydrological model. Cai, et al. [8] establish the correlation between rainfall and non-point source pollution load in research area by analyzing the water quality and hydrological monitoring data in Weihe Basin, then she calculate the total non-point source pollution load of single rainfall in watershed. Zhou et al. [9] analyze the monitoring data of rainfall and rainfall runoff pollutants in Zhenjiang ancient canal and establish the rainfall-runoff pollution equation. Furthermore, he uses the grey theory to forecast the rainfall in the future and get the total annual load of rainfall runoff pollution.

Up to now, the most study of the pollution load of rainfall runoff in Watershed only give the total amount of non-point source pollution load in single rainfall, there is few study on the process of pollution load changing with time of raining. So, this article establishes the relationship between the concentration of pollutant source and cumulative runoff by the monitoring value of water and water quality of main river in Xili Reservoir. Furthermore, we give the progress of non-point source pollution load flux changing with time of a typical rainfall.

\section{Situation of Typical Study Area}

Xili reservoir is located in the Pearl River Delta in the upper reaches of Shahe River, and it is also in Shenzhen Nanshan District Xili Street. Its water area is about $4.6 \mathrm{~km}^{2}$ and total storage capacity is about $3.41 \times 10^{7} \mathrm{~m}^{3}$. There are three main river in Xili reservoir which are Baimang River, Makan River and Dakan River respectively. Xili reservoir is one of the important drinking water source library of Shenzhen City. The catchment area and geographical parameters of control sections of the main inflow rivers are shown in Figure 1 and Table 1.

Xili reservoir basin is located in the low latitude subtropical area. Its annual average temperature is $22.4^{\circ} \mathrm{C}$, and rainfall distribute uneven during the year that the rainfall from April to September in flood season is $85 \%$ of the year. The rivers in Xili reservoir are rainy river and runoff, flow rate and flood peak are closely related to rainfall. According to the statistics of inflow quantity from 1966 to 1993 , the annual inflow quantity is $1.99 \times 10^{7} \mathrm{~m}^{3}$, the ratio of water year 


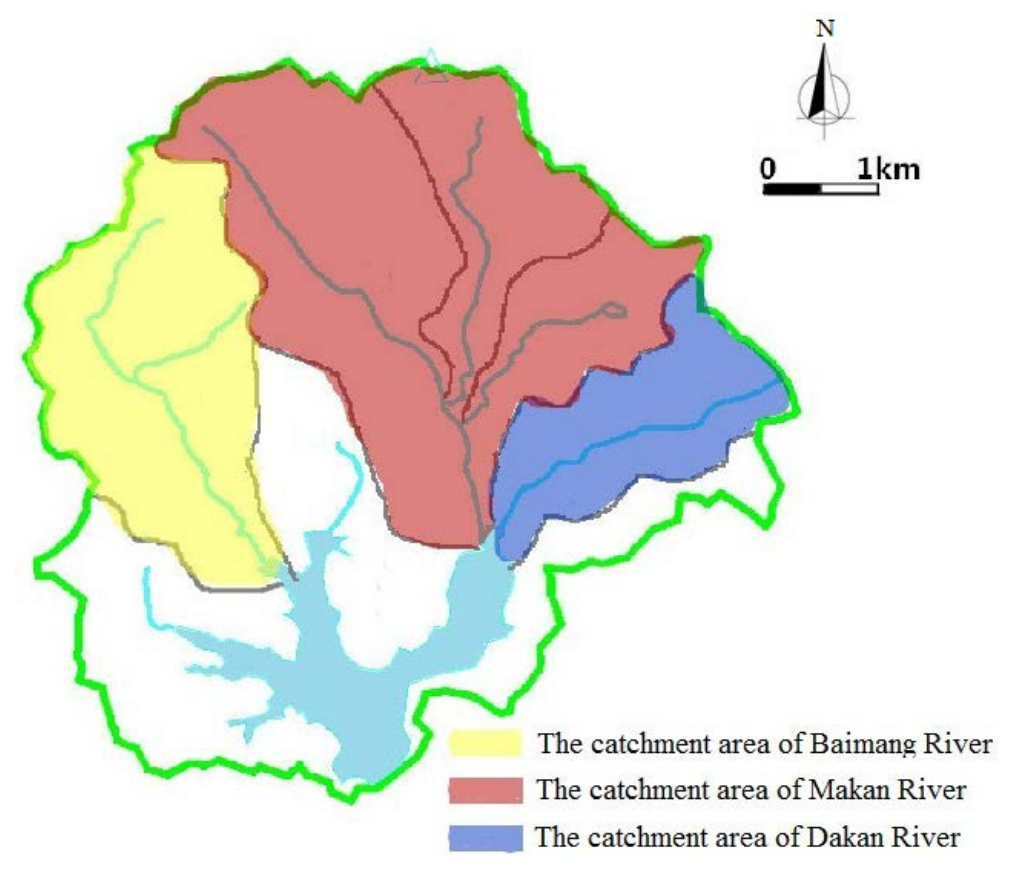

Figure 1. The catchment unit diagram of the main rivers in Xili reservoir.

Table 1. Geographic parameter table of the control section in the main rivers.

\begin{tabular}{cccc}
\hline Section name & Catchment area $/ \mathrm{km}^{2}$ & River length $/ \mathrm{km}$ & The average slope \\
\hline The control section of Baimang River & 3.36 & 4.7 & 0.014 \\
The control section of Baimang River & 9.69 & 3.3 & 0.021 \\
The control section of Baimang River & 2.23 & 2.78 & 0.022 \\
\hline
\end{tabular}

to dry year is $6: 1$ and the variation of annual inflow is consistent with the change of rainfall.

\section{Simulation of the Progress of Runoff Generation and Confluence in Small Watershed}

\subsection{The Manner of Simulating the Progress of Runoff Generation and Confluence in Small Watershed}

This article use integrated unit line method, which is recommended by relevant literature, to obtain the progress of the flood in control section of main rivers [10]. First, we get the design rainfall of point at different times, which is the center of catchment area, according to the contour map of rainstorm statistical parameters which is at different times in catchment area. Second, the design rainfall in the research area can be got by the curve of surface rainfall-point rainfall relationship. Then, according to the surface rainfall of same frequency but different duration and the design rainfall type, we get the process of design rainstorm. Next, the design progress of net rainfall calculates by computing runoff production. Finally, the design progress of flow, which is the progress of the main rivers flowing into the reservoir, calculates by convergence calculation. 


\subsection{The Simulation Results of the Progress of Runoff Generation and Confluence}

\subsubsection{The Simulation Results of the Progress of Rain}

This article use the maximum rainfall of single rain for each 5 years (it is 217 $\mathrm{mm}$ during 24 hours) as the design rainfall, and design the progress of rainstorm by the methods above. The design progress of rainstorm is shown in the Figure 2 .

\subsubsection{The Simulation Results of the Progress of Runoff Generation and Confluence}

According to the design progress of rainstorm and the simulation method of the progress of runoff generation and confluence, we get rainfall-runoff unit hydrograph and the design progress of flow for the watershed of the main rivers (Baimang River, Makan River, Dakan River). The result is shown in the Figure 3 and Figure 4.

As can be seen from the above figure, under the above conditions, the flow in control section of main rivers begins to appear when it rains for $2.33-2.5$ hours.

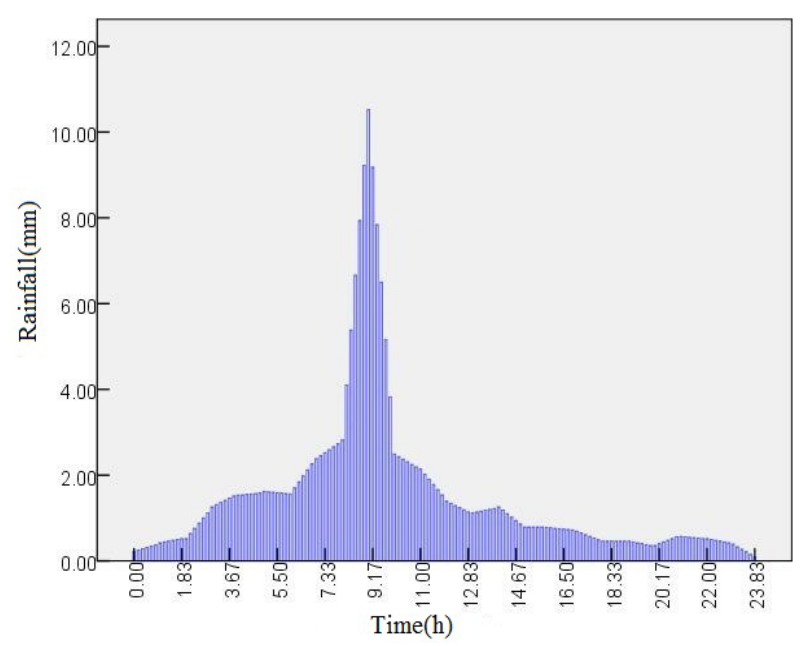

Figure 2. The design progress of rainstorm in Xili Reservoir.

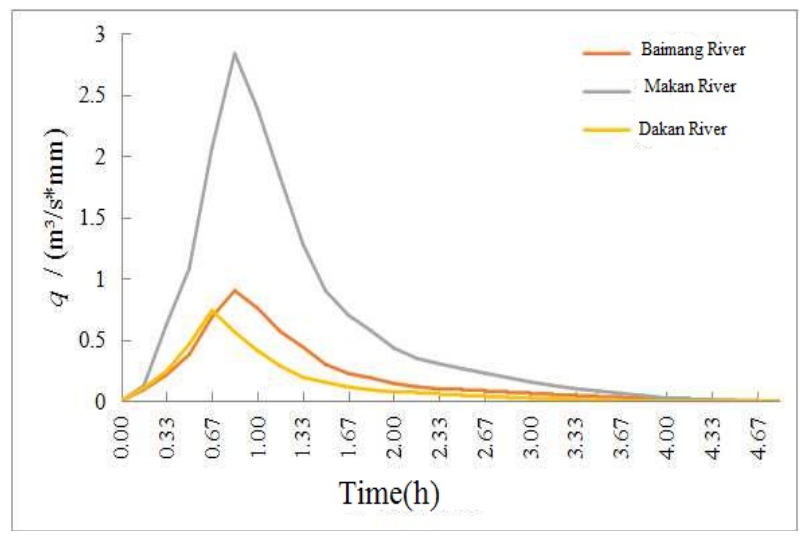

Figure 3. The runoff unit hydrograph of the watershed for the main rivers watershed. 


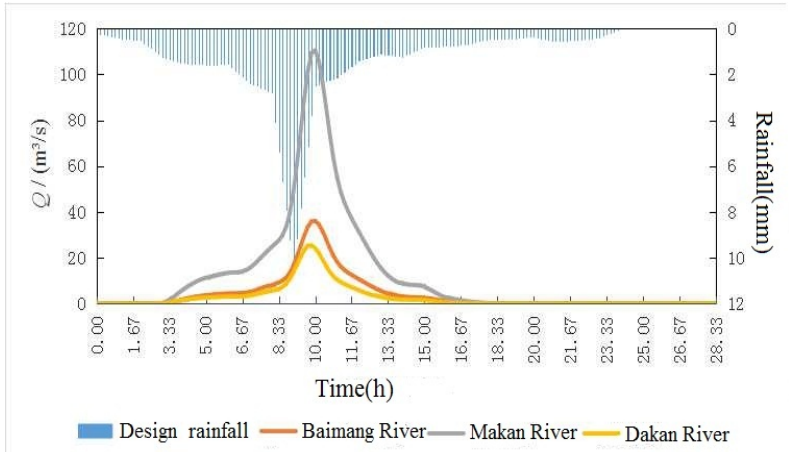

Figure 4. The progress of design rain and design runoff hydrograph corresponding of the main river.

The time difference between the maximum rainfall intensity of the design and the peak of the control section is $0.83-1$ hour.

\section{The Simulation Analysis of the Production Process of Non-Point Source Pollution Load}

\subsection{The Establishment of the Mathematical Model of the Watershed Surface Source Load}

He [11] believes that the concentration of pollutants decreases in rainoff until it is stable by the cumulative runoff increasing. Based on the rain which rainfall is $188 \mathrm{~mm}$ in the study area, the measured data of the water quality and the measured data of the rainfall in the entrance section are analyzed by the method of power function and exponential function. The results show that the index function can be used to study the correlation between the concentration of pollutants and the cumulative runoff. Among them, the function expression of the response relation mathematical function between measurement COD concentration which is of the main control section and the cumulative runoff or between measurement ammonia nitrogen concentration which is of the main control section and the cumulative runoff were respectively:

$$
\begin{aligned}
& y_{C O D B a i}=119.6258+1093.581 * \exp (-x / 31378.42) \\
& y_{N H 3-N B a i}=1.09985+37.30015 * \exp (-x / 20203.40) \\
& y_{C O D M a}=60.00308+597.65255 * \exp (-x / 11853.291) \\
& y_{N H 3-N M a}=1.85967+23.24033 * \exp (-x / 6233.355)
\end{aligned}
$$

In the calculation, $\mathrm{y}$ is the measurement contaminant concentration of the section, $\mathrm{mg} / \mathrm{L} ; \mathrm{X}$ is the cumulative runoff of the control section, $\mathrm{m}^{3}$.

The pollution load flux of control section is the sum of the point source pollution load and the non-point source pollution load. Since the generation process of non-point pollutants is affected by the rainfall process, the flux is closely related with the time process and the rainfall process. In the study area, it takes sampling detection to the flow of control section and the contaminant concentration time variation process respectively during rainfall period (April 19, 
2008), during the non rainfall period (February 20, 2008). According to the measured flow and pollutant concentration time variation process during the rainfall period, it can calculate cumulative runoff and cumulative pollutant flux of control section time variation process. Then, it deduct the effect of the base flow which is inflow the reservoir and cumulative pollutant flux of the base flow, cumulative runoff and cumulative non-point source pollutant flux time variation process can be obtained during the rainfall deduction. Finally, the dynamic response curve and response equation which is between non-point source pollutant concentration and cumulative runoff can be got by mathematical fitting. The results are shown in Figure 5 and Figure 6. Among them, the function expression of the response relation mathematical function between non-point source COD concentration which is of the main control section and the cumulative runoff or between non-point source ammonia nitrogen concentration which is of the main control section and the cumulative runoff were respectively:

$$
\begin{gathered}
\mathrm{y}_{\mathrm{COD} B a i}=98.75+842.74 * \exp (-x / 33146.42) \\
y_{\mathrm{NH} 3-\mathrm{N} B \mathrm{ai}}=0.091+0.0852 * \exp (-x / 40543.49) \\
y_{C O D M a}=12.34+542.9 * \exp (-x / 16666.67) \\
y_{N H 3-N M a}=1.076+21.66 * \exp (-x / 3904.24)
\end{gathered}
$$
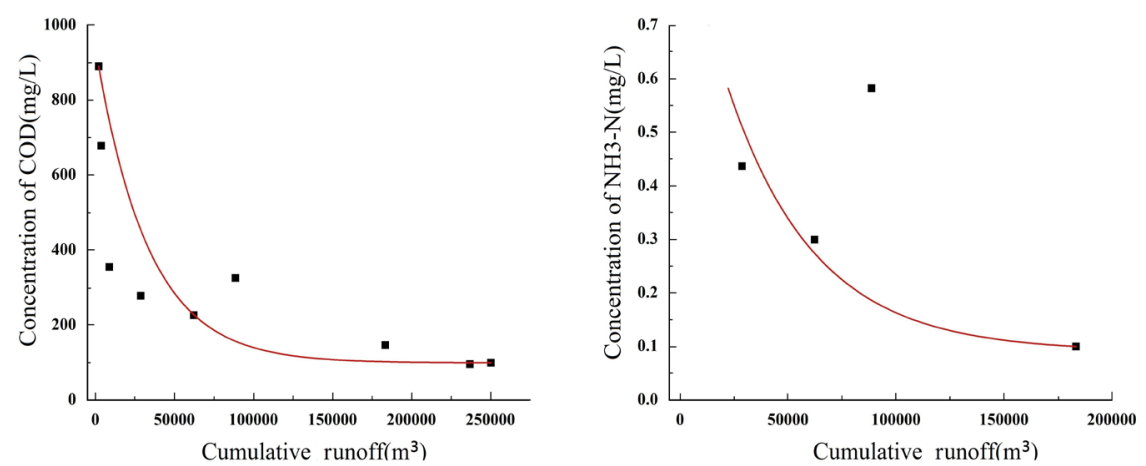

Figure 5. The curve of concentration of non-point source pollutants with accumulated runoff in Baiman River.
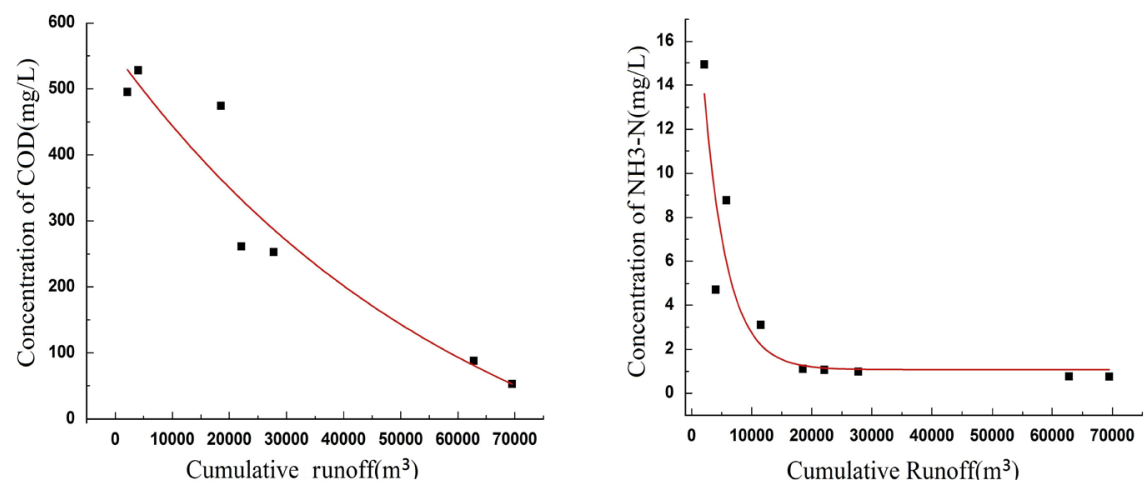

Figure 6. The curve of concentration of non-point source pollutants with accumulated runoff in Makan River. 
In the calculation, $\mathrm{y}$ is the non-point source contaminant concentration of the section, $\mathrm{mg} / \mathrm{L} ; \mathrm{X}$ is the cumulative runoff of the control section, $\mathrm{m}^{3}$.

\subsection{The Analysis of the Time Process of the Contamination Con- centration of the Reservoir in the Basin}

According to the correlation between non-point source pollutant concentration and cumulative runoff in Baimang River, Makan River and Dakan River, and the time variety progress of design runoff in Baimang River, Makan River and Dakan River, it can get cumulative runoff and its corresponding non-point source pollutant concentration in different times. Then, based on the time variation progress of cumulative runoff, it get the time variety progress of non-point source pollutant concentration which flow into the reservoir (the time variation progress of non-point source COD pollutant concentration in the control section of Baimang River and Makan River is shown in Figure 7).

Due to the difference of the increment of cumulative runoff in unit time and the variation of non-point source pollutants concentration when the same cumulative runoff flow from the control section during rainfall duration, nonpoint source COD concentration in main rives decrease at different rates, until finally tends to be stable. The initial COD concentration in the Baimang River basin was $941 \mathrm{mg} / \mathrm{L}$, it gradually stabilizes at 9.83 hours, and the steady concentration was about $98 \mathrm{mg} / \mathrm{L}$. The initial COD concentration in the Makan River basin was $555 \mathrm{mg} / \mathrm{L}$, it gradually stabilize at 6.50 hours, and the steady concentration was about $12 \mathrm{~m} \mathrm{~g} / \mathrm{L}$.

\subsection{The Analysis of the Time Varialation Process of the Flux Time of the Source of the Reservoir in the Basin}

According to the time variation process of non-point source pollutants concentration in main rivers of the study area and the time variation process of design runoff, the time variation process of non-point source pollutants flux can be get (the time variation progress of non-point source COD pollutant flux in the control section of Baimang River and Makan River is shown in Figure 8).

As can be seen from the above figure, the non-point source COD pollutant
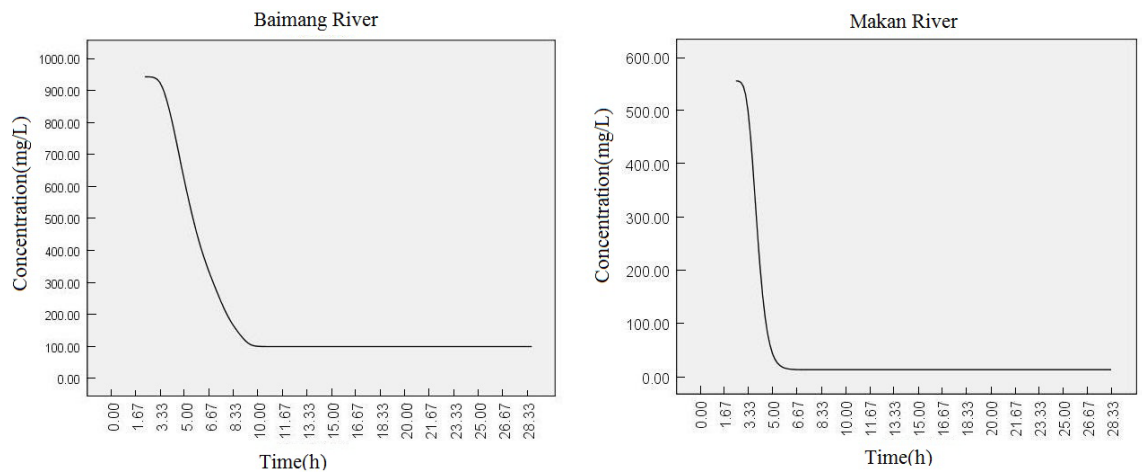

Figure 7. The curve of time variation progress of non-point source COD pollutant concentration in Baimang River and Makan River. 

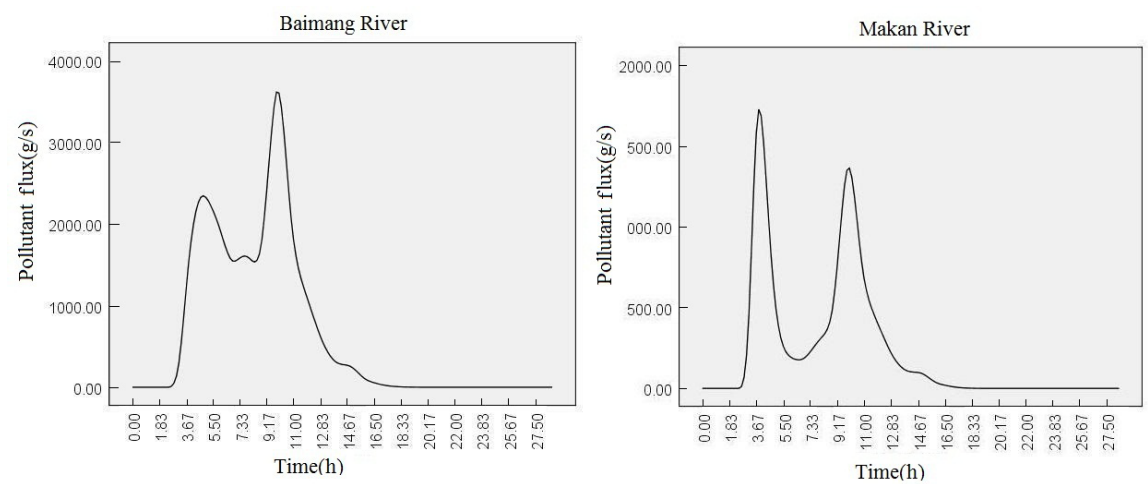

Figure 8. The curve of the time variation progress of non-point source COD pollutant flux in the control section of Baimang River and Makan River.

flux in the control section of the Baimang River and the Makan River are fluctuating with the increase of the rainfall time. This phenomenon is caused by varying the change rate of the contaminant concentration at the same time as design runoff in control section. For example, when the rain of Baimang River occurred $2.50 \mathrm{~h}-4.83 \mathrm{~h}$, the non-point source pollutant concentration of control section decrease more smoothly, but the runoff of control section increase relatively fast, so the non-point source pollutant flux is increasing. During the period of $4.83 \mathrm{~h}-7.00 \mathrm{~h}$, with the non-point source pollutant concentration of control section decrease rapidly and the runoff of control section increase slowly, the non-point source COD pollutant flux decrease.

\section{Conclusions}

1) The time variation progress of non-point source pollutant flux in study area which is based on the time series data of runoff and water quality which is simultaneous observation of control section in Xili Reservoir has considered the loss of the process of non-point source pollutant from where it generates to control section. This manner improves the accuracy of simulation calculation.

2) Because the time between runoff and pollution which is produced from the rain and the progress of the rain are different. The non-point source pollutant load of catchment for the main rivers began to enter the reservoir after the rain occurred for period of time. The non-point source pollutant concentration achieved peak when the runoff remitted to control section; then it decreased at a slower rate for a relatively short period of time. Afterwards, the concentration of non-point source pollutants decreased rapidly by the increase of the runoff.

3) Through the study of runoff and pollution generation process, it is found that the proportion of non-point source pollution load in the initial runoff is greater. For example, under the maximum rain for each 5 years in the study area, the non-point source COD pollution load of the runoff which is produced from the first 10 hours accounted for $70.98 \%$ of the total non-point source COD pollution load in the runoff which is produced from the whole rainfall process. The non-point source ammonia nitrogen pollution load of the runoff which is 
produced from the first 10 hours accounted for $74.27 \%$ of the total non-point source ammonia nitrogen pollution load in the runoff which is produced from the whole rainfall process.

\section{Acknowledgements}

This research was supported by the Research Program for the key technologies of the Sewage Outlet Setting in Deepwater Region.

\section{References}

[1] Cai, S.W., Pei, X.M., Zhang, Y.L., et al. (2006) Research on Agricultural Diffuse Pollution and Controlling Technology. Journal of Soil and Water Conservation, 20, 192-195. (In Chinese)

[2] Zhao, Y.X., Liu, S.H. and Zhang, R.G. (2007) The Agricultural Non-Point Pollution and Measures of Prevention and Control. Inner Mongolia Environmental Science, No. 1, 9-12. (In Chinese)

[3] Wang, Y.H. (2007) Pollution of City Rainfall Runoff and Its Controlling Measures. Shanxi Architecture, 33, 184-185. (In Chinese)

[4] Wang, L., Huang, Y.F. and Wang, G.Q. (2010) Review of Urban Non-Point Source Pollution Models. Environment Sciences, 31, 2532-2540. (In Chinese)

[5] Park, S.Y., Lee, K.W., Park, I.H., et al. (2008) Effect of the Aggregation Level of Surface Runoff Fields and Sewer Network for a SWMM Simulation. Desalination, 226, 328-337. https://doi.org/10.1016/j.desal.2007.02.115

[6] Liu, M. (2012) A Thesis Submitted in Partial Fulfillment of the Requirements for the Degree of Master of Engineering. Thesis, Huazhong University of Science and Technology, Hubei. (In Chinese)

[7] Long, T.Y., Liang, C.D., Li, J.C., et al. (2008) Forecasting the Pollution Load of Non-Point Pollution Sources Imported to the Three Gorges Reservoir. Acta Science Circumstantiae, No. 3, 574-581. (In Chinese)

[8] Cai, M., Li, H.E. and Zhuang, Y.T. (2005) Rainfall Deduction Method for Estimating Non-Point Source Pollution Load for Watershed. Journal of Northwest Sci-Tech University of Agriculture and Forestry (Natural Science Edition), No. 4, 102-106. (In Chinese)

[9] Zhou, M.T., Hu, X.D., Zhang, S.D., et al. (2015) Development of the Method to Estimate the Annual Load of Rainfall-Runoff Non-Point Source Pollution-A Case Study in Zhenjiang Ancient Canal. Chinese Journal of Mechanical Engineering, No. 8, 1381-1386. (In Chinese)

[10] Rui, X.F., Liu, N.J., Ling, Z., et al. (2012) Development and Inspiration of Unit Hydrograph. Advance in Science and Technology of Water Resources, No. 2, 1-5. (In Chinese)

[11] He, L. (2011) Research on Surface Contaminants Washoff Rule and the First Flush Effect with Artificial Rainfall Simulation. Thesis, Wuhan University of Technology, Hubei. (In Chinese) 
Submit or recommend next manuscript to SCIRP and we will provide best service for you:

Accepting pre-submission inquiries through Email, Facebook, LinkedIn, Twitter, etc. A wide selection of journals (inclusive of 9 subjects, more than 200 journals)

Providing 24-hour high-quality service

User-friendly online submission system

Fair and swift peer-review system

Efficient typesetting and proofreading procedure

Display of the result of downloads and visits, as well as the number of cited articles Maximum dissemination of your research work

Submit your manuscript at: http://papersubmission.scirp.org/

Or contact wjet@scirp.org 